\title{
Personal utility and genomic information: Look before you leap
}

\author{
Scott D. Grosse, PhD ${ }^{I}$, Colleen M. McBride, PhD', James P. Evans, MD, PhD , \\ and Muin J. Khoury, MD, $P h D^{4}$
}

In thenth $\mathrm{n}$ this issue, Foster et al. ${ }^{1}$ argue that the utility of personal genomic information and the level of evidence that is required to document utility depend on the context and audience. Similarly, others have suggested that the utility of genomic information be considered from three perspectives: the public health perspective, which emphasizes health improvements on a population level; the clinical perspective, which emphasizes the use of genomic information in diagnostic thinking and therapeutic choice; and the personal perspective, which may consider genomic information as having potential value per se, positive or negative, regardless of its clinical use or health outcomes. ${ }^{2}$

Foster et al. ${ }^{1}$ suggest that personal utility can be measured and used to identify which individuals are most likely to benefit from or be harmed by personal genomic information. In the clinical setting, patient decision aids provide individuals and clinicians with tools for assessing potential benefits and harms of clinical treatment options. For example, a number of decision aids have been developed to help individuals considering genetic testing for hereditary breast cancer assess the probabilities and importance of medical and nonmedical consequences. ${ }^{3}$ No one doubts that there will be challenges to developing decision aids to help consumers assess the potential benefits and risks of genomic information associated with slight elevations in risk of disease.

Foster et al. ${ }^{1}$ also propose that measures of personal utility be combined with measures of utility in terms of health outcomes to generate aggregate estimates of benefits. However, they do not provide practical advice on how to do so. The subjective and multidimensional nature of utility makes it challenging to measure, as has been true in the case of metrics of quality of life (QOL). Measures of health-related QOL, both generic and disease specific, do not seem to tap into a single underlying construct. ${ }^{4}$ Other QOL measures that encompass nonhealth dimensions of well-being represent even more diversity. This experience suggests that reaching agreement on an acceptable

From the ${ }^{1}$ National Center on Birth Defects and Developmental Disabilities, Centers for Disease Control and Prevention, Atlanta, Georgia; ${ }^{2}$ Social and Behavioral Research Branch, National Human Genome Research Institute, National Institutes of Health, Bethesda, Maryland; ${ }^{3}$ Department of Genetics, University of North Carolina at Chapel Hill, Chapel Hill, North Carolina; and ${ }^{4}$ Office of Public Health Genomics, Centers for Disease Control and Prevention, Atlanta, Georgia.

Scott D. Grosse, PhD, National Center on Birth Defects and Developmental Disabilities, Centers for Disease Control and Prevention, 1600 Clifton Road, Mail Stop E88, Atlanta, GA 30333. E-mail: sgrosse@cdc.gov.

Disclaimer: The findings and conclusions in this report are those of the authors and do not necessarily represent the official position of the Centers for Disease Control and Prevention, the National Institutes of Health, or the U.S. Department of Health and Human Services.

Disclosure: The authors declare no conflict of interest

Submitted for publication May 1, 2009.

Accepted for publication May 4, 2009

Published online ahead of print July 18, 2009

DOI: 10.1097/GIM.0b013e3181af0a80 construct and rigorous assessments of personal utility will be challenging.

Research has shown that most individuals in families affected by Alzheimer disease who were given the opportunity to learn their apoliopoprotein E (APOE) genotype status perceived the results to have personal utility. They felt that it helped them prepare for the future, despite a lack of intervention options, and those tested generally did not experience adverse psychological effects. ${ }^{5,6}$ However, genetic testing for Alzheimer disease may be the high water mark for personal utility, as such strong predictive ability will be the exception and not the rule in personal genomics.

The aggregation of personal and clinical utility to estimate overall utility is most readily addressed through economic methods, but these too pose major challenges. Foster et al. ${ }^{1}$ mentioned cost-effectiveness analysis, which is used to assess the costs of different societal or health care approaches relative to achieving a particular outcome, e.g., saving lives or preventing disease. A subtype known as cost-utility analysis uses the quality-adjusted life-year, a measure that incorporates a certain type of health-related QOL information. ${ }^{7}$ Although these methods have been used to evaluate newborn screening and genetic tests, ${ }^{8,9}$ they have rarely shaped policy decisions, and lack of data has undercut their reliability. ${ }^{10}$ Furthermore, these methods are not suited to address personal utility. ${ }^{11}$

A monetary metric for personal utility, "willingness-to-pay," is often used in cost-benefit analysis to aggregate social welfare across sectors. ${ }^{12}$ However, most cost-benefit analyses of health interventions only include morbidity and mortality outcomes. ${ }^{12} \mathrm{~A}$ limitation to willingness-to-pay methods (i.e., individuals are asked how willing they would be to pay a specified amount for a service) is that people have difficulty making hypothetical choices in unfamiliar contexts. ${ }^{13}$ Low public awareness of personalized genomics, both its potential benefits and harms, makes consideration of such testing an unfamiliar context for most people.

Other approaches also might be used to measure personal utility. Discrete choice experiment with conjoint analysis is a method derived from marketing research that assesses respondents' relative preferences between pairs of scenarios with multiple dimensions. ${ }^{14}$ This method has been used to assess average preferences over a range of attributes, such as potential harms and benefits of intervention and process attributes. ${ }^{15,16}$ Economists have used the discrete choice experiment/conjoint analysis method to assess individual values and preferences for genomic information, regardless of how the information might be used. For example, a study from Canada used this type of method to elicit parents' stated willingness-to-pay for diagnostic testing for genetic causes of intellectual disability through array genomic hybridization. ${ }^{17}$ Although receiving a specific diagnosis does not alter how most children are managed medically, ${ }^{18}$ parents may perceive value from understanding their child's diagnosis and their own recurrence risk. Similarly, individuals in families with a history of breast cancer often choose to be tested for genetic mutations even though they do not 
intend to use the information to guide management or prevention strategies. ${ }^{19}$

How to balance domains of health-related utility and personal utility in determining overall utility of personalized genomics was raised at a December 2008 multidisciplinary workshop convened by the National Institutes of Health and Centers for Disease Control and Prevention. ${ }^{20}$ Serious conceptual, empirical, and political challenges face the aggregation and calibration of information on various dimensions of utility. On a technical level, different measures can be aggregated if they do not overlap. Politically, the desirability of aggregating medical and nonmedical aspects of personal utility depends on the particular audience. For regulators who must decide which tests should be made available, a broad measure of well being that incorporates all dimensions of utility seems appropriate. From a payer or public health perspective, it may not be. ${ }^{10}$ Health care payers and public health authorities typically have a specific mission to improve health.

In conclusion, we welcome calls by Foster et al. ${ }^{1}$ and the National Institutes of Health and Centers for Disease Control and Prevention workshop participants for the development of metrics of personal utility. We encourage full consideration of conceptually based, formative research, and cutting-edge economic, social, and behavioral science methods to assess utility and QOL implications of personal genomic information. Such conceptual and empirical research must involve scientists from a broad range of disciplines. In addition, continued dialogue among stakeholders is needed regarding areas of oversight and responsibility for the provision of personal genomic information, including scientifically accurate interpretation of test results. It should not be presumed that policy makers will or will not find metrics of personal utility to be relevant to the specific questions that they are asked to address.

\section{REFERENCES}

1. Foster MW, Mulvihill JJ, Sharp RR. Evaluating the utility of personal genomic information. Genet Med In press.

2. Grosse SD, Khoury MJ. What is the clinical utility of genetic testing? Genet Med 2006;8:448-450.

3. Iredale R, Rapport F, Sivell S, et al. Exploring the requirements for a decision aid on familial breast cancer in the UK context: a qualitative study with patients referred to a cancer genetics service. J Eval Clin Pract 2008; $14: 110-115$.
4. Saban KL, Stroupe KT, Bryant FB, Reda DJ, Browning MM, Hynes DM. Comparison of health-related quality of life measures for chronic renal failure: quality of well-being scale, short-form-6D, and the kidney disease quality of life instrument. Qual Life Res 2008;17:1103-1115.

5. Chao S, Roberts JS, Marteau TM, Silliman R, Cupples LA, Green RC. Health behavior changes after genetic risk assessment for Alzheimer disease: the REVEAL Study. Alzheimer Dis Assoc Disord 2008;22:94-97.

6. Green R, Roberts J, Cupples L, et al. Disclosure of APOE genotype for risk of Alzheimer's disease. $N$ Eng $J$ Med In press.

7. Drummond MF, Sculpher MJ, Torrance GW, O'Brien BJ, Stoddart GL. Methods for the economic evaluation of health care programs, 3rd ed. Oxford: Oxford University Press, 2005.

8. Carlson JJ, Henrikson NB, Veenstra DL, Ramsey SD. Economic analyses of human genetics services: a systematic review. Genet Med 2005;7:519-523.

9. Rogowski W. Genetic screening by DNA technology: a systematic review of health economic evidence. Int J Technol Assess Health Care 2006;22:327-337.

10. Grosse SD. Cost effectiveness as a criterion for newborn screening policy decisions. In: Bailey MA, Murray TH, editors. Ethics and newborn genetic screening: new technologies, new challenges. Baltimore: Johns Hopkins University Press. 2009:58-88.

11. Grosse SD, Wordsworth S, Payne K. Economic methods for valuing the outcomes of genetic testing: beyond cost-effectiveness analysis. Genet Med 2008; 10:648-654.

12. Krupnick AJ. Valuing health outcomes: policy choices and technical issues Washington, DC: Resources for the Future, 2004. Available at: http:// www.rff.org/rff/Documents/RFF-RPTValuingHealthOutcomes.pdf. Accessed November 1, 2004

13. Watson V, Ryan M. Exploring preference anomalies in double bounded contingent valuation. $J$ Health Econ 2007;26:463-482.

14. Phillips KA, Johnson FR, Maddala T. Measuring what people value: a comparison of "attitude" and "preference" surveys. Health Serv Res 2002; $37: 1659-1679$

15. Wordsworth S, Ryan M, Skatun D, Waugh N. Women's preferences for cervical cancer screening: a study using a discrete choice experiment. Int $J$ Technol Assess Health Care 2006;22:344-350.

16. Constantinescu F, Goucher S, Weinstein A, Smith W, Fraenkel L. Understanding why rheumatoid arthritis patient treatment preferences differ by race. Arthritis Rheum 2009;61:413-418.

17. Regier DA, Friedman JM, Makela N, Ryan M, Marra CA. Valuing the benefit of diagnostic testing for genetic causes of idiopathic developmental disability: willingness to pay from families of affected children. Clin Genet 2009;75:514-524.

18. Saam J, Gudgeon J, Aston E, Brothman AR. How physicians use array comparative genomic hybridization results to guide patient management in children with developmental delay. Genet Med 2008;10:181-186.

19. Cappelli M, Surh L, Humphreys L, et al. Measuring women's preferences for breast cancer treatments and BRCA1/BRCA2 testing. Qual Life Res 2001;10:595-607

20. Khoury MJ, McBride C, Schully SD, et al. The scientific foundation for personal genomics: recommendations from an NIH-CDC multidisciplinary workshop. Genet Med In press. 